J. Lake Sci. (湖泊科学), 2012, 24(2): 273-281

http: //www.jlakes.org. E-mail : jlakes@niglas.ac.cn

(C) 2012 by Journal of Lake Sciences

\title{
内蒙古呼伦湖水量平衡计算与分析”
}

\author{
王志杰 ${ }^{1}$, 李畅游 ${ }^{1 * *}$, 李卫平 ${ }^{1,2}$, 张 生 $^{1}$ \\ ( 1 : 内蒙古农业大学水利与土木建筑工程学院, 呼和浩特 010018) \\ (2: 内蒙古科技大学能源与环境学院,包头 014010)
}

摘 要: 根据呼伦湖的实际水文过程, 计算 1963-1980 年月水量平衡, 在此基础上, 分析库容与径流、径流 + 降雨、径流 + 降雨 - 蒸发的相关性. 利用累积和分析水位、径流、降雨、蒸发年均值的突变情况,进而重点论述了 2000 年后水位持续降 低的原因. 同时, 探讨各水平衡项的年内分布规律及相互关系. 结果表明,2000 年后水位的急剧降低是气候变化 (暖干化) 造成的. 河川径流对水位的影响程度最大, 其次为湖面降雨. 每年 4.5 月, 冰封期积累的降雪融化渗人地下补给湖泊, 其他 时间则由湖泊补给地下水.

关键词: 水面蒸发;水量平衡; 呼伦湖; 累积和

\section{Calculation and analysis of water balance in Lake Hulun, Inner Mongolia}

\section{WANG Zhijie ${ }^{1}$, LI Changyou ${ }^{1}$, LI Weiping ${ }^{1,2} \&$ ZHANG Sheng ${ }^{1}$}

(1: Water Conservancy and Civil Engineering College, Inner Mongolia Agricultural University, Hohhot 010018, P. R. China)

(2:School of Environment and Energy Resources, Inner Mongolia University of Science and Technology, Baotou 014010, P. R. China)

Abstract: The correlation between the storage capacity and runoff, runoff + precipitation, runoff + precipitation - evaporation was analysed at the basis of monthly water balance calculation in the period of 1963 and 1980 according to the real hydrological processes of the research site. At the same time, the intermediate-term changes in the mean value of water level, runoff, precipitation and evaporation were detected with the cumulative sum technique in order to find the reason of water level dropping after 2000 . Meanwhile, the distribution and mutual relations of water balance terms in a year was analyzed. Results show that: climate change exhibited a warmer and dryer trend in recent years that might be the major cause for water resources deficit after 2000. The crucial influence on water level comes from runoff, followed by precipitation on the water surface. In April and May of each year, accumulated melt water infiltrate the soil and then recharge the lake, while in the other time the groundwater recharged by the lake.

Keywords: Open water evaporation; water balance; Lake Hulun; the cumulative sum technique

呼伦湖是中国第五大淡水湖, 也是东北第一大湖, 被称作呼伦贝尔草原的“肾”.该湖于 1992 年被 批准为国家级自然保护区, 2002 年 1 月被列人国际重要湿地名录,同年 11 月被联合国教科文组织人 与生物圈计划纳为世界生物圈保护区网络 ${ }^{[1-3]}$. 呼伦湖滋润着周边草原, 调节着整个草原气候, 与大 兴安岭共同构筑了中国北方的生态屏障, 在保障东北乃至华北地区生态安全方面发挥着不可替代 的作用.

呼伦湖流域近代水文过程受到人为干扰比较强烈, 流域内生态水文过程严重紊乱,生态环境严重退化, 突出表现为呼伦湖水位降低, 水域面积萎缩及草原沙化、退化. 据监测, 近 $5 \mathrm{a}$ 来湖泊水位连续下降 $2.3 \mathrm{~m}$. 水 量的不断减少造成水环境逐步恶化, 目前呼伦湖水体已基本呈中度富营养化水平 ${ }^{[4]}$. 同时, $1965-1985$ 年湖

* 国家自然科学基金项目 (51069007,50969005,40901262)、内蒙古自然科学基金项目 (2010MS0713,2010MS0611) 和 内蒙古自治区重大项目和内蒙古教育厅科研项目 (NJ09051) 联合资助. 2011-05-11 收稿; 2011-08-14 收修改 稿.王志杰,女,1983 年生,博士研究生;E-mail : wangzhijie0807@ gmail. com.

** 通信作者; E-mail:nndlichangyou@163.com. 
周草原每年以 $5 \%$ 的速度退化, $1985-1997$ 年以 $10 \%$ 的面积加速退化 ${ }^{[5]}$.

呼伦湖水情变化属于干旱内陆流域湖泊环境热点问题之一, 同时, 呼伦湖流域跨中、蒙、俄边界, 相关资 料的系统性较差, 给呼伦湖问题的研究带来了难度. 虽然问题被广泛关注,但研究深度和可信服结论性认识 有限. 本文试图采用多种途径, 利用有限的数据, 对呼伦湖水量平衡进行分析, 为呼伦湖相关研究提供借鉴 作用.

\section{1 研究区概况}

呼伦湖也称达妻湖, 湖面呈不规则长方形, 长轴为西南至东北方向 (图 1), 湖长 $93 \mathrm{~km}$, 平均宽度 $25 \mathrm{~km}$, 周长 $447 \mathrm{~km}$, 当湖水位达到历史较高水位 $545.33 \mathrm{~m}$ 时, 蓄水量为 $138 \times 10^{8} \mathrm{~m}^{3}$, 湖水面积 $2339 \mathrm{~km}^{2}$, 最大水深 $8.0 \mathrm{~m}$, 平均水深 5 6 m. 湖区属于中温带大陆性季风气候, 多年平均气温为 $3 \sim 5^{\circ} \mathrm{C}$, 最大湿度可达 $80 \%$, 全 年最大风速 $5.35 \mathrm{~m} / \mathrm{s}$, 降雨量为 $256 \mathrm{~mm}$, 蒸发量为 $1500 \mathrm{~mm}$, 主要集中在 4-11 月, 占全年 $94.4 \%$, 而 $12 、 1-$ 3 月仅占 $5.6 \%(1960-2008$ 年统计).

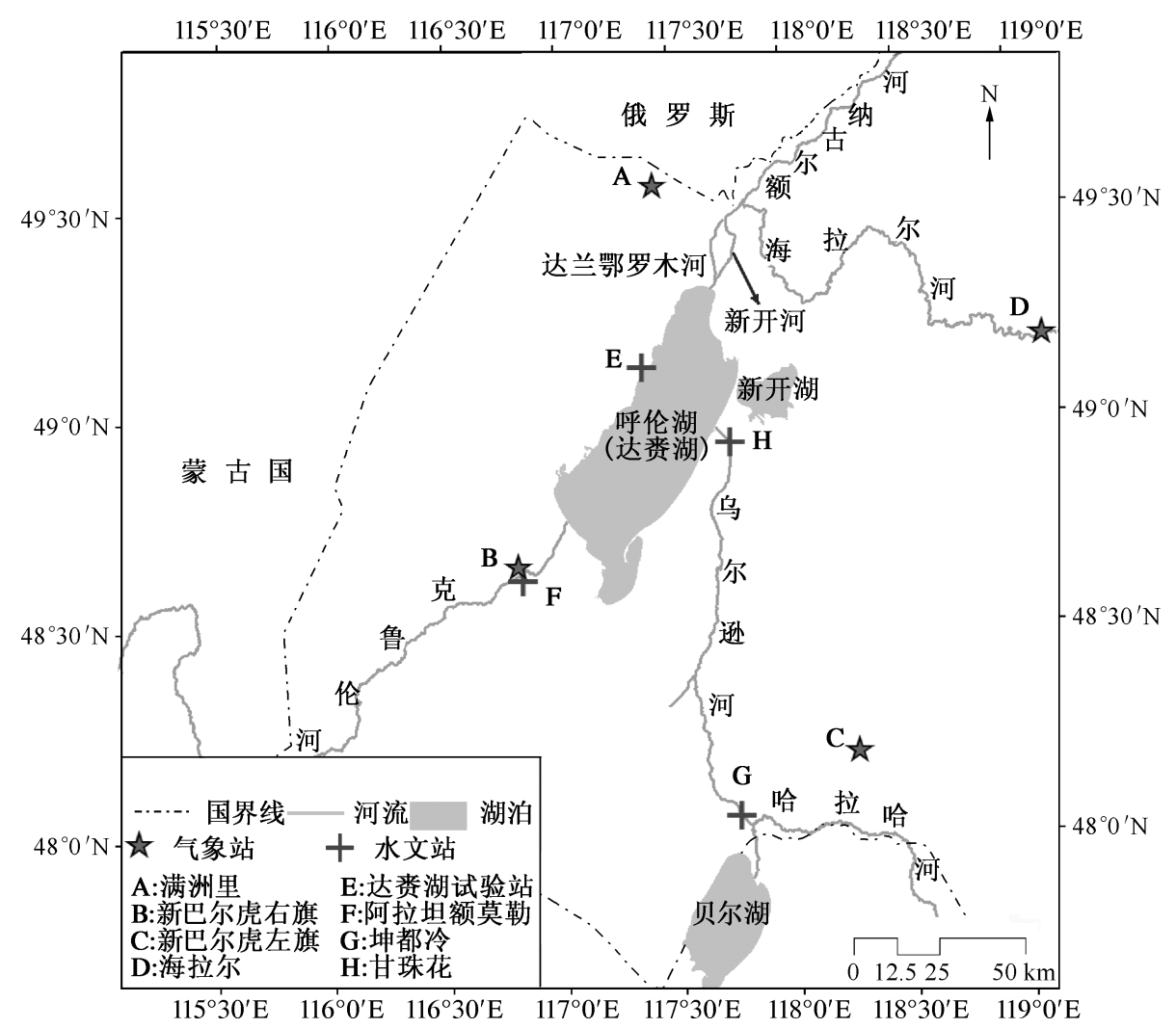

图 1 呼伦湖位置及水文、气象站点

Fig. 1 The location of Lake Hulun and distribution of meteorological and hydrological stations

\section{2 站点与数据}

\section{1 水文与气象}

湖周边原设有阿拉坦额莫勒、坤都冷、甘珠花和达秉湖试验站四个水文站, 均建于 1950s 末, 其中甘珠花 站、达妻湖试验站分别于 1971 、1980 年撤销, 其他两个站仍在使用中. 气象站位于湖周临近旗县境内 (图 1 , 表 1). 
表 1 水文站及气象站观测数据种类及年限

Tab. 1 The data of meteorological station and stream flow gauging station

\begin{tabular}{|c|c|c|c|c|c|c|}
\hline \multirow{2}{*}{ 水文站 } & \multirow{2}{*}{ 位置 } & \multicolumn{5}{|c|}{ 资料 } \\
\hline & & 降雨 & 蒸发 & 径流 & \multicolumn{2}{|c|}{ 水位 } \\
\hline 阿拉坦额莫勒 & $48^{\circ} 38^{\prime} \mathrm{N}, 116^{\circ} 50^{\prime} \mathrm{E}$ & $1963-2009$ & $1996-2009$ & $1963-2009$ & \multicolumn{2}{|c|}{$1963-2009$} \\
\hline 坤都冷 & $48^{\circ} 04^{\prime} \mathrm{N}, 117^{\circ} 45^{\prime} \mathrm{E}$ & $1961-2009$ & $1966-2009$ & $1961-2009$ & \multicolumn{2}{|c|}{-} \\
\hline 甘珠花 & $48^{\circ} 57^{\prime} \mathrm{N}, 117^{\circ} 45^{\prime} \mathrm{E}$ & - & - & $1959-1971^{1)}$ & \multicolumn{2}{|c|}{$1959-1971^{1)}$} \\
\hline 达春湖试验站 & $49^{\circ} 08^{\prime} \mathrm{N}, 117^{\circ} 22^{\prime} \mathrm{E}$ & $1960-1980$ & $1960-1980$ & - & \multicolumn{2}{|c|}{$1960-1980,1981-2008^{2)}$} \\
\hline 气象站 & 位置 & 降雨 & 日照时数 & 相对湿度 & 温度 & 风速 \\
\hline 满洲里 & $49^{\circ} 34^{\prime} \mathrm{N}, 117^{\circ} 26^{\prime} \mathrm{E}$ & $1960-2008$ & $1960-2008$ & $1960-2008$ & $1960-2008$ & $1960-2008$ \\
\hline 新巴尔虎右旗 & $48^{\circ} 40^{\prime} \mathrm{N}, 116^{\circ} 49^{\prime} \mathrm{E}$ & $1960-2008$ & $1960-2008$ & $1960-2008$ & $1960-2008$ & $1960-2008$ \\
\hline 新巴尔虎左旗 & $48^{\circ} 13^{\prime} \mathrm{N}, 118^{\circ} 16^{\prime} \mathrm{E}$ & $1960-2008$ & $1960-2008$ & $1960-2008$ & $1960-2008$ & $1960-2008$ \\
\hline 海拉尔 & $49^{\circ} 13^{\prime} \mathrm{N}, 119^{\circ} 45^{\prime} \mathrm{E}$ & $1960-2008$ & $1960-2008$ & $1960-2008$ & $1960-2008$ & $1960-2008$ \\
\hline
\end{tabular}

1): 逐年数据, 其他为逐日数据;2): 李狎预测值.

\section{2 水位-面积-库容}

通过孙标利用水深反演模型推算的湖底高程 ${ }^{[6]}$ 数据获得水位一面积、水位-库容关系曲线 (图 2), 采 用 Matlab 对三者关系进行拟合 (图 3). 为了检验湖 底高程数据的精度, 利用 $\langle\text { 呼伦湖志 }\rangle^{[7]}$ 中历年最高 水位一面积一蓄水量关系进行比较, 相对误差最大为 $6 \%$, 说明该数据精度较高, 能够满足本文计算 要求.

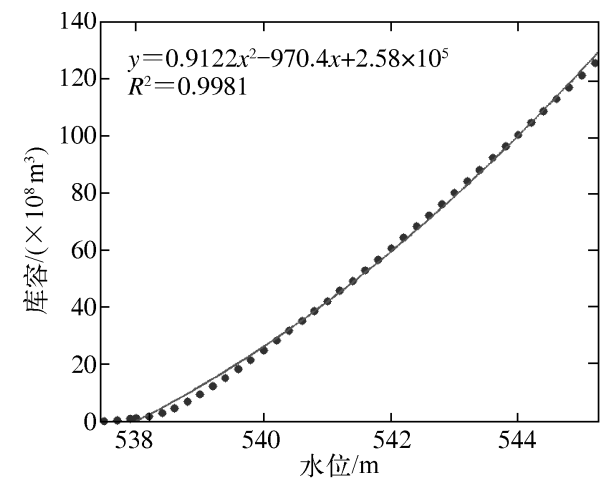

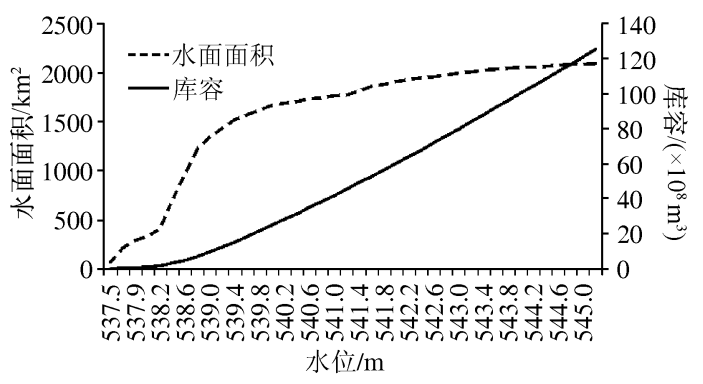

图 2 水位-面积、水位-库容关系曲线

Fig. 2 Relationship curves between lake level - water area and lake level - volume

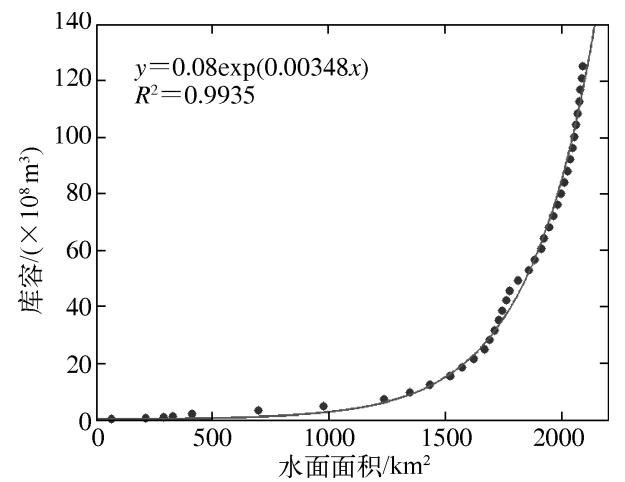

图 3 水位-库容、水面面积-库容拟合曲线

Fig. 3 Fitting curves between lake level - volume and water area - volume

\section{3 水量平衡模型}

某时段出、人湖泊水量之差与湖泊增 (减) 水的关系,可用水量平衡方程式 ${ }^{[9]}$ 表示: 


$$
\frac{\Delta V}{\Delta t}=A(h)(P-E)+Q_{\text {in }}+Q_{\text {out }}
$$

式中, $\Delta t$ 为计算时段 (天、月、年), $\Delta V$ 为湖泊库容变化量 $\left(\mathrm{m}^{3}\right)$, 当时段末水量多于时段初, $\Delta V$ 为正值, 反之 为负值, $A$ 为湖泊水面面积 $\left(\mathrm{m}^{2}\right), A$ 是水位 $(h)$ 的函数, $P$ 为湖面降雨量 $(\mathrm{mm}), E$ 为湖面蒸发量 $(\mathrm{mm}), Q_{\mathrm{in}}$ 为 人湖水量 $\left(\mathrm{m}^{3}\right), Q_{\text {out }}$ 为出湖水量 $\left(\mathrm{m}^{3}\right)$.

根据呼伦湖的实际情况, 将水量平衡方程表示为:

$\frac{\Delta V}{\Delta t}=A(h)(P-E)+Q_{\text {河流入 }}+Q_{\text {坡面汇流 }}+Q_{\text {地下人 }}-Q_{\text {河流出 }}-Q_{\text {地下出 }}=A(h)(P-E)+Q_{\text {河流人 }}-Q_{\text {河流出 }}+Q_{\text {余项 }}$

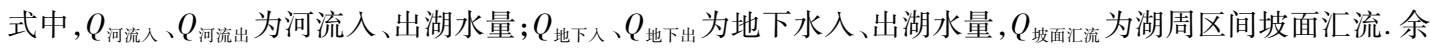
项表示为:

$$
Q_{\text {余项 }}=Q_{\text {坡面汇流 }}+Q_{\text {地下人 }}-Q_{\text {地下出 }}
$$

\section{4 水平衡项计算}

\section{1 湖面降雨量}

达妻湖试验站使用人工式雨量筒观测降雨, 精度有限且存在漏测现象, 气象站采用自记式仪器, 其数 据相对精确. 满洲里、新巴尔虎右旗气象站与达责湖试验站降雨量分布最相近, 取其平均值作为湖面降 雨量.

\section{2 河川径流量}

乌尔逊河上的坤都冷水文站与甘珠花水文站进行年径流量回归分析, 计算流人呼伦湖的实际水量. 据 调查,达兰鄂罗木河于 1958 年被堵, 达妻湖泄水工程,即新开河于 1971 年 9 月投人使用. 该人工河的流量没 有实测数据, 目前了解到两种关于流量的记载: 第一, 当呼伦湖水位超过 $544.8 \mathrm{~m}$ 时, 按照闸门设计流量正常 泄流, 即 $40.7 \mathrm{~m}^{3} / \mathrm{s}^{[7]}$; 第二, 自 1971 年 9 月至 1979 年 9 月,通过新开河共泄水 $17.5 \times 10^{8} \mathrm{~m}^{3}$. 本文采用第一 种记载的方式进行计算.

\section{3 湖面蒸发量}

蒸发是自然界水文循环过程中的主导因素之一, 是水量平衡要素的重要组成部分. 由于 1980 年后达妻 湖试验站缺失观测数据以及蒸发血折算系数各异 ${ }^{[6,9-10]}$, 所以本文水面蒸发量通过模型计算获得. 蒸发量的 测量、计算方法有很多,例如水量平衡法 ${ }^{[11-12]}$ 、能量平衡法 ${ }^{[13-14]}$ 、质量传输法 ${ }^{[15]}$ 、彭曼公式法 ${ }^{[16-17]}$ 等. 其中彭 曼公式法使用较为普遍,并被 FAO (Food and Agricultural Organization of United Nations) 推荐. 但是彭曼公式 需要的气象数据及经验参数较多, 很多气象站点不能满足模型的要求. 为此, Valinantzas ${ }^{[18]}$ 对彭曼公式进行 了简化处理,仅利用温度、相对湿度、日照和风速等常规气象指标计算蒸发量 $\left(E_{\mathrm{PEN}}\right)$.

$$
\begin{aligned}
E_{\mathrm{PEN}}= & 0.051(1-\alpha) R_{\mathrm{S}} \sqrt{T+9.5}- \\
& 0.188(T+13)\left(\frac{R_{\mathrm{S}}}{R_{\mathrm{A}}}-0.194\right)\left[1-0.00014\left(0.7 T_{\max }+0.3 T_{\min }+46\right)^{2} \sqrt{\frac{R H}{100}}\right]+ \\
& 0.049\left(T_{\max }+16.3\right)\left(1-\frac{R H}{100}\right)(0.54 U)
\end{aligned}
$$

式中, $\alpha$ 为水面太阳辐射反射系数, 开阔水面取值为 $0.08, R_{\mathrm{S}}$ 为太阳辐射 $\left(\mathrm{MJ} /\left(\mathrm{m}^{2} \cdot \mathrm{d}\right)\right), R_{\mathrm{A}}$ 为大气顶太阳 辐射 $\left(\mathrm{MJ} /\left(\mathrm{m}^{2} \cdot \mathrm{d}\right)\right), R H$ 为相对湿度 $(\%), U$ 为 $2 \mathrm{~m}$ 处风速 $(\mathrm{m} / \mathrm{s}) . T$ 为平均温度, $T=\left(T_{\text {max }}+T_{\text {min }}\right) / 2, T_{\text {max }}$ 与 $T_{\min }$ 分别为最高、最低温度.

四个气象站中满洲里的蒸发量计算值与观测值吻合最好, 故选其作为湖面蒸发量. 由式 (4) 看出, 该简 化式仅适合于平均温度高于 $-9.5^{\circ} \mathrm{C}$ 的情况. 对于呼伦湖而言, 只能计算 4-11 月逐日蒸发量 (占全年蒸发 量的 $94.4 \%)$, 而 $11-3$ 月份蒸发量采用年内蒸发量分布比例计算. 
将月蒸发量计算值与达秉湖试验站的观测值 进行对比 (图 4), 蒸发血折算系数采用 $0.62^{[19]}$, 可

以看出, 观测值与计算值的相关系数达到 0.937 , 说明模拟的湖面蒸发量是合理的.

\section{4 余项}

余项中包括湖周坡面汇流、湖水与地下水交换 量,这两项的量值目前没有观测资料记载. 利用 Penman 公式分别计算 1960-2008 年湖周气象站 所在草原的逐日蒸发量, 取其平均值与逐日降雨量 进行比较 (图 5 ) 结果表明全年内逐日蒸发量高于 降雨量, 但是在 11 至翌年 4 月内, 降雨量很小且以 降雪形式存在, $5 、 10$ 月, 蒸发增加的幅度远超过降 雨,所以此期间几乎不能形成坡面汇流. 6-9 月, 当短时间内降雨强度超过土壤下渗速率时,形成坡 面汇流. 所以, 这里假设 10 月至翌年 5 月, 余项仅 为地下水与湖水的交换量, 而 6-9 月还包括湖周 坡面汇流. 余项的量值为库容差与其他水平衡项的

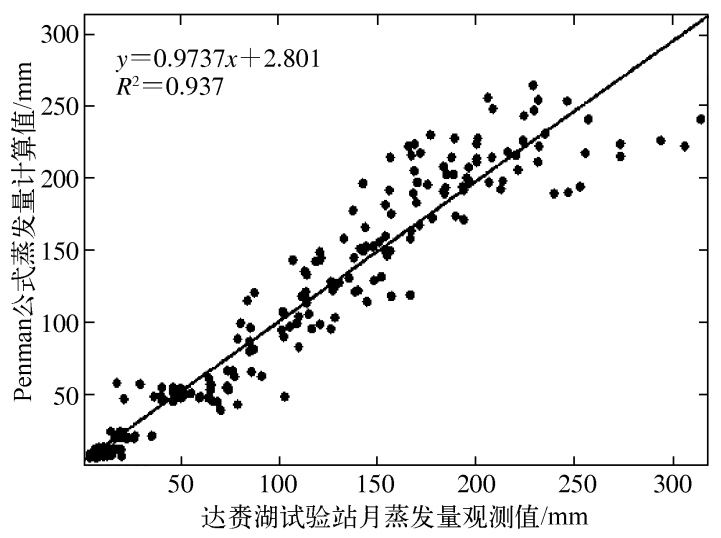

图 4 蒸发量计算值与达秉湖试验站月蒸发量 观测值对比

Fig. 4 Comparision of observed monthly evaporation of meteorological station in Lake Hulun and simulated value

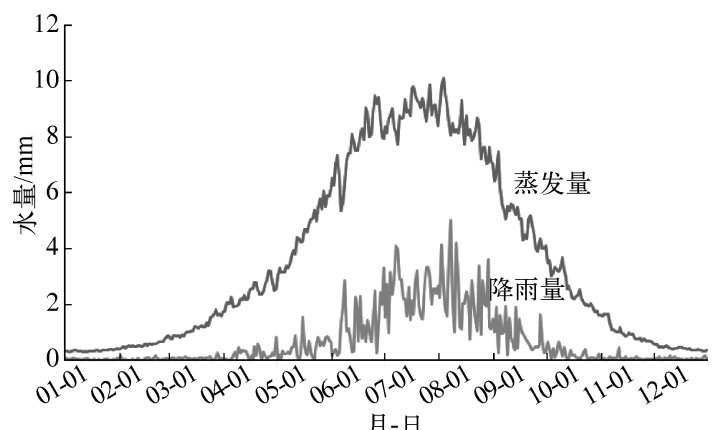

图 5 1960-2008 年呼伦湖周边草原逐日蒸发量 和降雨量变化

Fig. 5 Daily evaporation and precipitation of grassland around Lake Hulun from 1960 to 2008

选择 1963-1980 年段进行月水量平衡计算, 结果表明年内库容差的变化不一,有正有负, 呈现 正常的波动状态 (图 7). 但是, 1972 年和 1980 年内的库容差几乎全部为负, 湖泊水量在持续减少, 而在蒸 发、余项没有明显变化的情况下, 径流、降雨达到最低. 这说明湖泊水量的变化与径流、降雨存在着直接的关 系. 在此基础上, 对不同月份的库容差与径流、径流 + 降雨、径流 + 降雨 - 蒸发以及水位差与径流 + 降雨之 间的相关性进行分析,结果见表 2 .

库容差与径流 $(Q)$ 、径流 + 降雨 $(Q+P)$ 、径流 + 降雨 - 蒸发 $(Q+P-E)$ 之间的相关系数均达到 0.65 以 上, 大小顺序为: $R_{(Q+\mathrm{P})}^{2}>R_{(Q)}^{2}>R_{(Q+\mathrm{P}-\mathrm{E})}^{2}$, 平均值分别为 $0.8,0.7,0.67$ 左右 (表 2$)$. 可以推断出径流对于水 位变动的影响程度最大, 降雨次之.

1-4、11、12 月份, 库容差、径流的相关系数与库容差、径流 + 降雨的接近, 而 5-10 月, 差距较大, 其原 因是在冰封期降雨主要以降雪的形式存在, 不能立刻与湖水交换, 湖泊则主要依赖于两条补给河流. 在非冰 封期, 强降雨引起的季节性河流开始汇人湖中, 此外地下水的活动较冰封期活跃, 这些因素均对水平衡产生 影响, 使得湖泊水量与径流 + 降雨的关系不显著. 


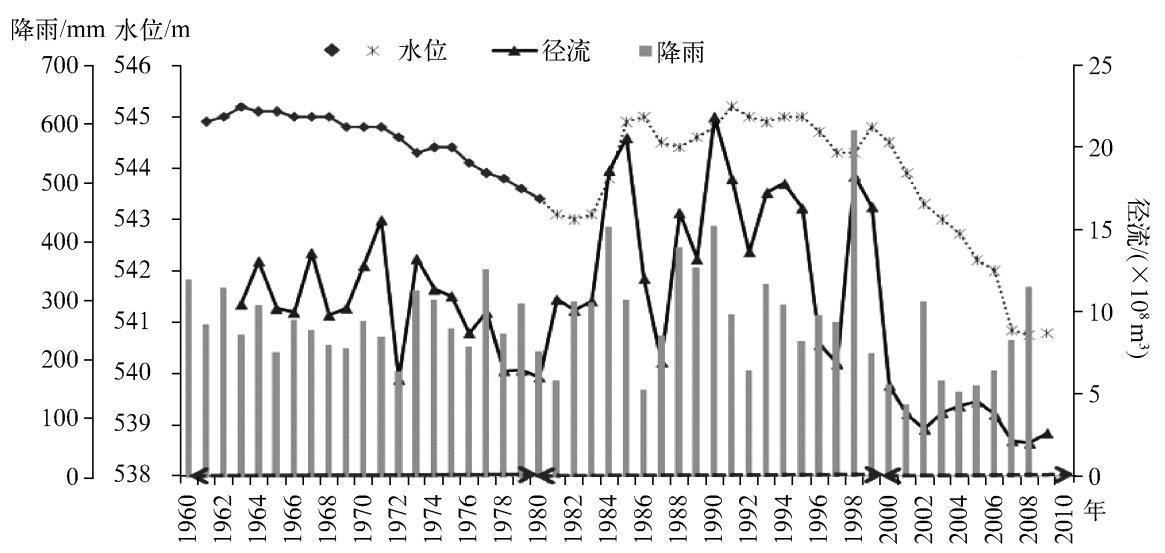

图 6 1960-2010 年水位、降雨量、径流量 (乌尔逊河 + 克鲁伦河)变化 (1960-1980 年水位为逐日观测值,1981 年后水位为李站预测值)

Fig. 6 Yearly series of lake level, precipitation and rainfall( $1960-2010)$
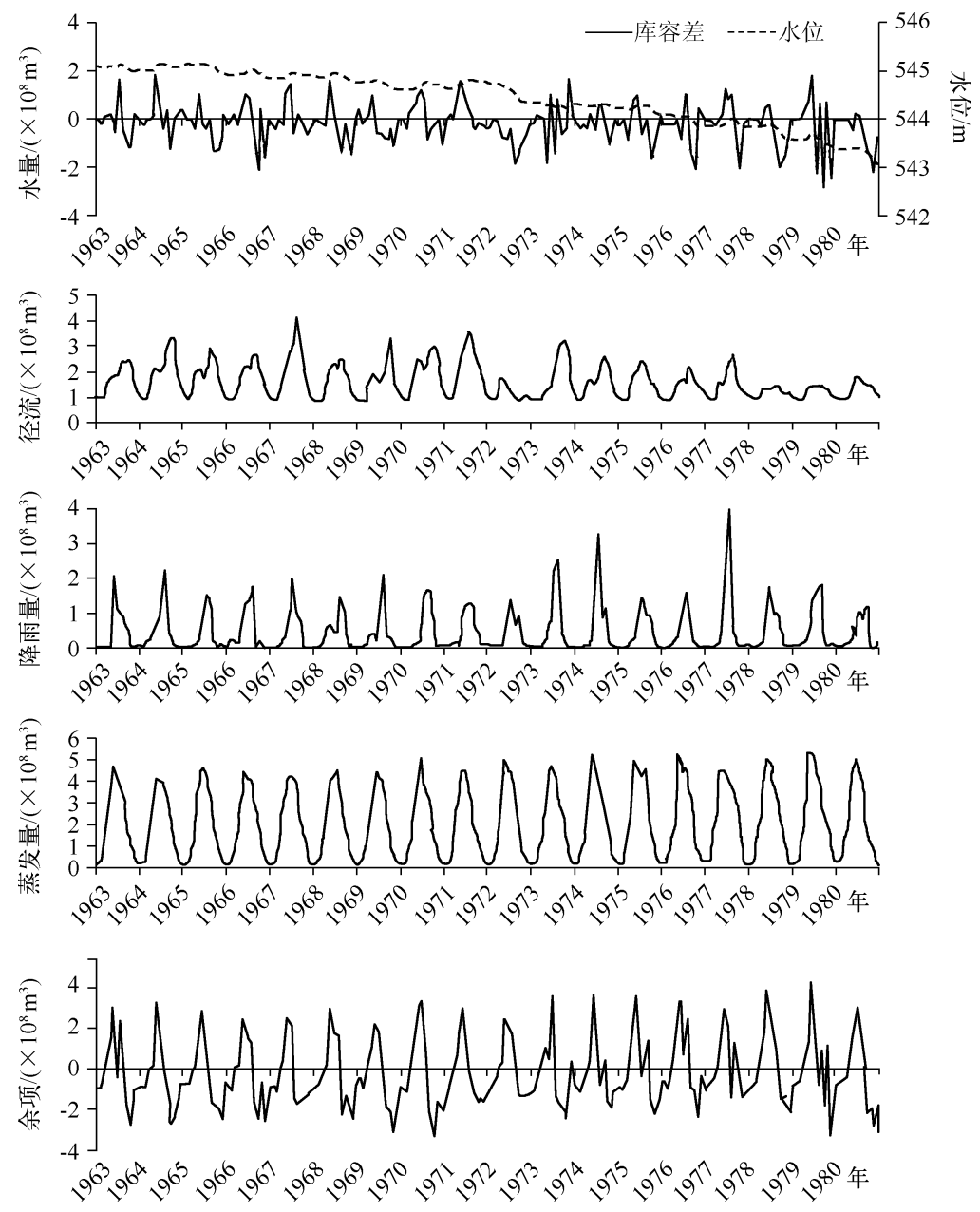

图 7 1963-1980 年水量平衡项变化情况

Fig. 7 Water balance terms in the period from 1963 to 1980 
表 2 水量平衡项相关分析

Tab. 2 Correlation analysis between water balance terms

\begin{tabular}{|c|c|c|c|c|c|c|c|c|c|c|c|c|}
\hline \multirow{2}{*}{ 月份 } & \multicolumn{3}{|c|}{$\Delta V=a Q-b$} & \multicolumn{3}{|c|}{$\Delta V=c(Q+P)-d$} & \multicolumn{3}{|c|}{$\Delta V=e(Q+P-E)+f$} & \multicolumn{3}{|c|}{$\Delta h=m(Q+P)-n$} \\
\hline & $a$ & $b$ & $R^{2}$ & $c$ & $d$ & $R^{2}$ & $e$ & $f$ & $R^{2}$ & $m$ & $n$ & $R^{2}$ \\
\hline 1 & 0.875 & 0.11 & 0.851 & 0.798 & 0.14 & 0.863 & 0.486 & 0.16 & 0.618 & 0.038 & 0.713 & 0.898 \\
\hline 2 & 0.866 & 0.11 & 0.776 & 0.758 & 0.13 & 0.848 & 0.472 & 0.18 & 0.610 & 0.036 & 0.667 & 0.852 \\
\hline 3 & 0.763 & 0.1 & 0.841 & 0.693 & 0.12 & 0.872 & 0.545 & 0.27 & 0.736 & 0.033 & 0.632 & 0.876 \\
\hline 4 & 0.755 & 0.09 & 0.818 & 0.685 & 0.12 & 0.867 & 0.541 & 0.29 & 0.737 & 0.032 & 0.625 & 0.872 \\
\hline 5 & 0.734 & 0.09 & 0.733 & 0.692 & 0.11 & 0.806 & 0.578 & 0.31 & 0.737 & 0.034 & 0.638 & 0.811 \\
\hline 6 & 0.571 & 0.07 & 0.651 & 0.551 & 0.10 & 0.758 & 0.561 & 0.30 & 0.68 & 0.026 & 0.466 & 0.725 \\
\hline 7 & 0.593 & 0.08 & 0.669 & 0.563 & 0.10 & 0.784 & 0.567 & 0.29 & 0.687 & 0.027 & 0.521 & 0.789 \\
\hline 8 & 0.592 & 0.08 & 0.684 & 0.556 & 0.11 & 0.735 & 0.521 & 0.31 & 0.682 & 0.025 & 0.487 & 0.712 \\
\hline 9 & 0.706 & 0.09 & 0.652 & 0.67 & 0.12 & 0.755 & 0.546 & 0.28 & 0.682 & 0.032 & 0.608 & 0.732 \\
\hline 10 & 0.739 & 0.09 & 0.661 & 0.674 & 0.12 & 0.743 & 0.531 & 0.29 & 0.632 & 0.033 & 0.609 & 0.666 \\
\hline 11 & 0.945 & 0.11 & 0.849 & 0.811 & 0.14 & 0.851 & 0.642 & 0.36 & 0.614 & 0.039 & 0.722 & 0.753 \\
\hline 12 & 0.917 & 0.11 & 0.851 & 0.791 & 0.14 & 0.862 & 0.633 & 0.36 & 0.722 & 0.038 & 0.716 & 0.866 \\
\hline
\end{tabular}

2000 年后, 湖水位、降雨、径流都发生了巨大的变化, 为了摸清其原因, 这里引入累积距平值 ${ }^{[20]}$ (简称 $S$ 值) 的概念. 该方法已经被证实为一种检验实测数据系列平均值发生突变的有效工具, 表达式为:

$$
S_{i}=\sum_{i=1}^{i}\left(x_{i}-\bar{x}\right)
$$

其中, $x_{i}$ 为实测值, $\bar{x}$ 为系列的平均值. 当实测值大于长系列平均值时, 斜率为正, 反之斜率为负, 持续的正、 负斜率用来鉴别系列平均值的中间突变.

经过计算,降雨、蒸发、径流、水位的平均值分别为 $265.89 \mathrm{~mm} 、 1173.18 \mathrm{~mm} 、 10.78 \times 10^{8} \mathrm{~m}^{3} 、 544.1 \mathrm{~m}$ (1960-2008 年). 水位、降雨、径流、蒸发的 $S$ 值变化存在一定的规律性 (图 8 ). 首先, 水位、降雨、径流变化 趋势近乎一致, 1975 年后呈下降趋势, 于 1983 年达到最小值, 之后急剧上升, 于 2000 年达到最大, 接着剧烈 下降,而蒸发则完全相反. 其次, 各项 $S$ 值变化趋势的转变几乎发生在同一时期. 最后, 对比 1975-1983 年和 2000 年后两个时段内 $S$ 值变化幅度, 水位与降雨、径流相同, 变化幅度小于后一时段, 而蒸发则相反, 这就说 明 2000 年后水位急剧下降的主要原因并不是蒸发的缓慢增加, 而可能是降雨、径流的剧烈下降. 经统计, 较 2000 年前蒸发量增加 $0.5 \times 10^{8} \mathrm{~m}^{3} / \mathrm{a}$, 降雨减少 $0.75 \times 10^{8} \mathrm{~m}^{3} / \mathrm{a}$, 径流减少 $1.8 \times 10^{8} \mathrm{~m}^{3} / \mathrm{a}$. 目前所调查的结 果显示中国境内没有企业大量使用克鲁伦河与乌尔逊河河水, 而且径流量、降雨、蒸发发生突变的时间如此 吻合, 也进一步说明河流截留的可能性不大. 所以,2000 年后湖泊水位降低主要是气候变化造成的. 白美兰、 赵慧颖等利用 46 年气象和卫星遥感监测资料研究呼伦湖区域气候变化特征, 结果表明进人 21 世纪后小雨强 度和干燥事件显著增强, 导致了干旱事件的频发和强度增加 ${ }^{[21]}$, 气候呈暖干化趋势 ${ }^{[22]}$, 致使湖面降雨量减少, 蒸发量增加, 河流径流量减少, 进而湖泊总损失水量增加, 水位持续下降. 这与前面相关性分析的结果相符.

计算 1963-1980 年段水平衡项各月多年平均值表明,降雨、径流自 3 月开始增加,增加的幅度远小于蒸 发, 而在 4、5 月份, 库容差为正值, 水位增加. 同时, 余项在此段期间呈正值增加趋势 (图 9), 这说明余项对库 容产生了较大的影响. 前面定义余项在 4、5 月份仅为地下水与湖水的交换量, 那么库容在 4、5 月增加的原因 可能是由于自 11 月至次年 3 月, 历时 5 个月的累积降雪随着温度的回升, 开始融化并渗人土壤, 形成了地下 浅层径流, 并逐渐汇入湖泊. 同时, 地下水的活动也开始加剧. 为了进一步证实以上推断, 做以下计算. 湖周 汇流区在 11-3 月期间的总降雪量为 $6.99 \times 10^{8} \mathrm{~m}^{3}$, 而在 2-5 月期间, 余项累积为 $6.45 \times 10^{8} \mathrm{~m}^{3}$, 这说明库 容在 4、5 月增加的原因推断是可信的.

6 月之后, 径流、降雨仍在增加, 而库容差却呈负值. 其原因有两点, 第一, 虽然补给湖泊的径流、降雨在 增加, 但是两者的和仍小于湖面蒸发量, 所以湖泊呈亏损状态; 第二, 当融雪水退去后, 湖周面积近 $8100 \mathrm{~km}^{2}$ 的草地、沼泽地随着温度、太阳辐射、风速的升高, 蒸发量大大增加, 降雨不能抵消蒸发损失, 致使地下水位 

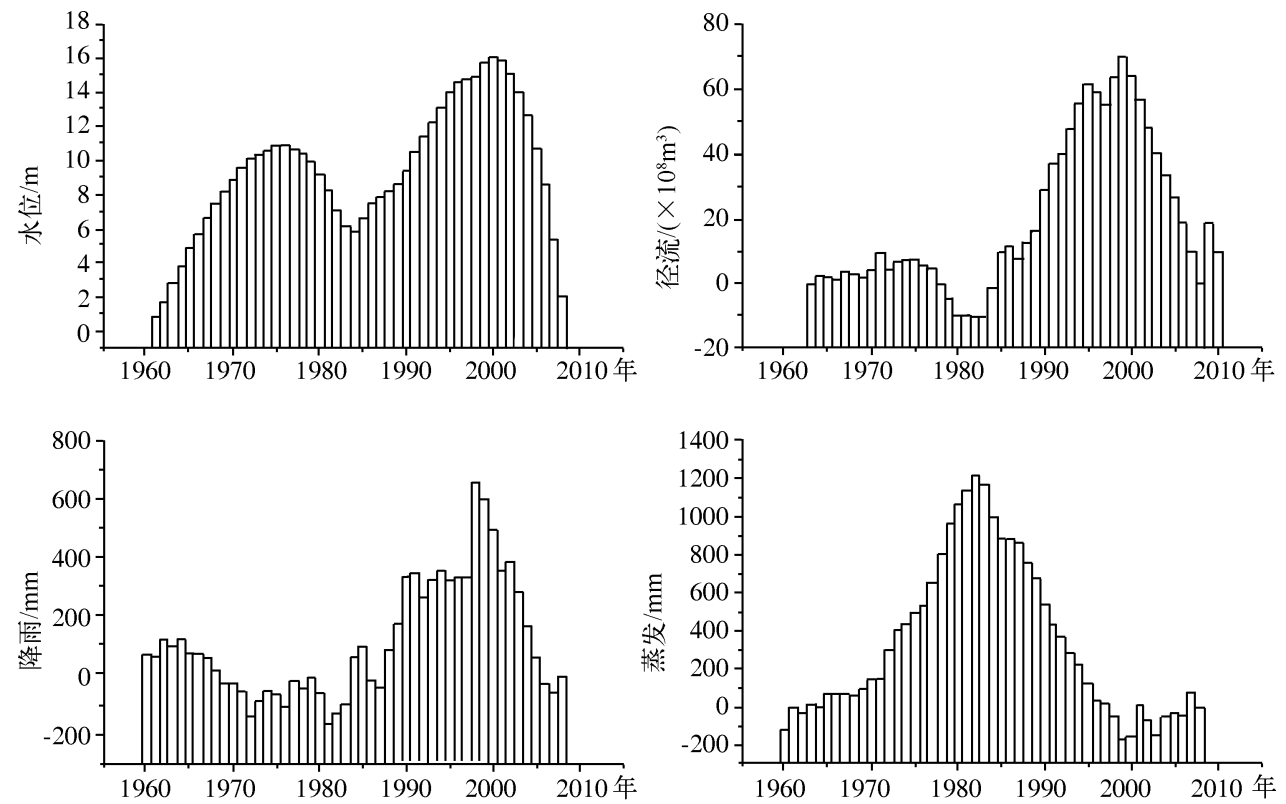

图 8 1960-2010 年降雨、径流、蒸发、水位累积和变化

Fig. 8 The cumulative sum of rainfall, runoff, evaporation, water level in the period of 1960 and 2010

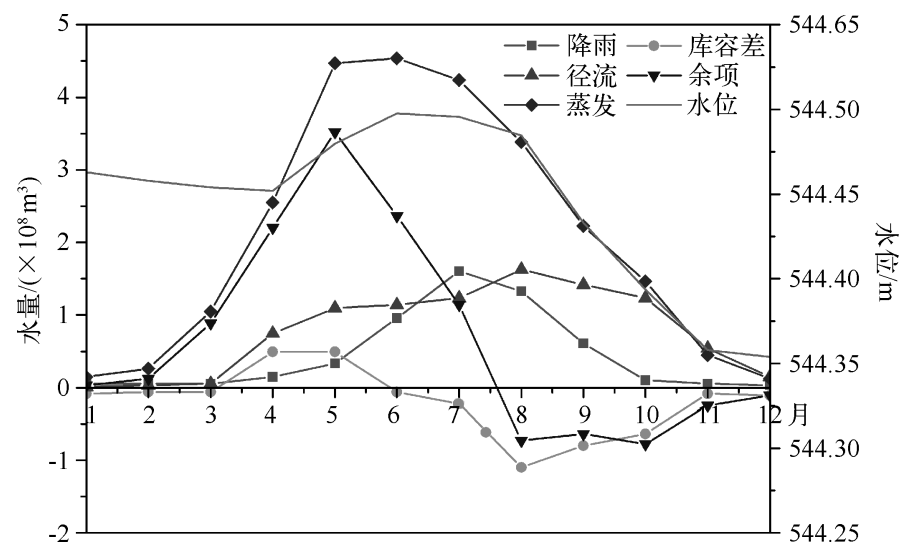

图 9 年内水平衡项变化情况

Fig. 9 Monthly distribution of water balance terms

逐渐降低, 补给湖水的作用逐渐减 弱,湖水开始补给地下水. 根据《呼伦 湖志》记载, 湖周地表径流为 $2.58 \times$ $10^{8} \mathrm{~m}^{3}$,而余项在 6-9 月期间总水 量为 $1.49 \times 10^{8} \mathrm{~m}^{3}$, 则湖泊补给地下 水为 $1.09 \times 10^{8} \mathrm{~m}^{3}$, 随后逐渐减少.

将本文水量平衡的计算结果与 已有研究进行对比,结果表明本文计 算结果与已有研究成果存在着一定 的差距(表 3), 这是由水平衡项的定 义、计算方法及计算时段、时间步长 不同造成的. 呼伦湖流域对于湖周的 坡面汇流、湖水与地下水之间相互作 用的研究较少,致使没有相对准确的 相关成果进行比较验证. 为了更为清

楚地了解该流域水文过程, 还需要借助相关模型进行深人研究.

表 3 呼伦湖水量 $\left(\times 10^{8} \mathrm{~m}^{3}\right)$ 平衡计算结果对比

Tab. 3 Comparison on results of water balance calculation

\begin{tabular}{|c|c|c|c|c|c|}
\hline 研究 & 降雨 & 蒸发 & 径流 & 其他 & \\
\hline 本文 & 5.29 & 24.65 & 径流 (克 +乌 - 新开) 10.23 & 余项 (湖周人流 + 地下水交换) & 83 \\
\hline 呼伦湖志 & 6.29 & 25.8 & 径流(克＋乌) 12.2 & 湖周地表径流 2.58 & 地下水补给 3.9 \\
\hline $\begin{array}{l}\text { 水面蒸发与水 } \\
\text { 量平衡估算 }\end{array}$ & 5.76 & 23.32 & 径流 (克 +乌) 12.07 & 湖周 (地表 + 地下) 入流 5.96 & 新开河 1.44 \\
\hline
\end{tabular}




\section{6 结论}

本文在对呼伦湖流域水文过程及水平衡项定义及计算的基础上, 进行月水量平衡计算及分析, 结果表 明:1） 2000 年后, 湖泊水位的持续降低是由气候变化造成的, 湖区降雨减少、蒸发增加导致湖面损失水量增 加, 同时河川径流量剧烈下降, 人湖水量相应减少;2）河川径流量对于水位变化的影响程度最为明显, 其次 为湖面降雨量; 3 ) 湖泊周边流域自 11 月至次年 3 月的累积降雪,融化并渗人地下补给湖泊,其水量为 6.45 $\times 10^{8} \mathrm{~m}^{3}$ 左右, 致使湖泊在 4、5 月份水量增加; 4) 6 月后, 融雪水退去后, 蒸发强于降雨, 地下水位降低, 湖泊 开始补给周边流域, $6-9$ 月补给地下水量约为 $1.09 \times 10^{8} \mathrm{~m}^{3}$ ( 坡面汇流为 $2.58 \times 10^{8} \mathrm{~m}^{3}$ ), 之后逐渐减少.

\section{7 参考文献}

［1］王素慧, 梁宏伟, 杨玉生. 呼伦湖湿地水环境治理对策. 内蒙古水利, 2006, (1): 35-36, 41.

[2] 颜文博, 张洪海, 张承德. 达责湖自然保护区湿地生物生境保护. 国土与自然资源研究, 2006, (2) : 47-48.

[ 3 ] 张晓晶, 李畅游, 张 生等. 呼伦湖沉积物重金属分布特征及生态风险评价. 农业环境科学学报, 2010, (1): 157-162.

[4] 韩向红，杨 持. 呼伦湖自净功能及其在区域环境保护中的作用分析. 自然资源学报, 2002,(6): 684-690.

[ 5 ] 严登华, 何 岩, 邓 伟等. 呼伦湖流域生态水文过程对水环境系统的影响. 水土保持通报, 2001, (5): 1-5.

[6 ] 基于空间信息技术的呼伦湖水量动态演化研究 [学位论文]. 呼和浩特: 内蒙古农业大学, 2010.

[7 ] 地方志编写委员会. 呼伦湖志 (续志一, 1987-1997). 呼和浩特: 内蒙古文化出版社, 1998: 44.

[ 8 ] Magali Troin, Vallet-coulomb C, Florence Sylvestre. Hydrological modeling of a closed lake( laguna Mar Chiquita, Argentina) in the context of 20th century climatic changes. Journal of Hydrolody, 2010, 393 : 233-244.

[9] 施成熙, 牛克源. 水面蒸发折算系数研究. 地理科学, 1986, 6 (4) : 305-313.

[10］李 拂, 马 巍, 叶柏生等. 呼伦湖水面蒸发及水量平衡估计. 水文, 2006,(5): 41-44.

[11] Guitjens JC. Model of alfalfa yield and evapotranspiration. Journal Irrigation and Drainage Engineering, 1982, ASCE 108 (IR3) : 212-222.

[12] Abtew W. Evaporation estimation for Lake Okeechobee in south Florida. Journal Irrigation and Drainage Engineering, 2001, ASCE 127 (3) : 140-146.

[13] Sturrock AM, Winter TC, Rosenberry OD. Energy-budget evaporation from Williams Lake: a closed lake in north central Minnesota. Water Resources Research, 1992, 28(6) : 1605-1617.

[14] Sacks LA, Lee TM, Radell MJ. Comparison of energy-budget evaporation. Losses from two morphologically different Florida seepage lakes. Journal of Hydrology, 1994, 156: 311-334.

[15] Singh VP, Xu CY. Evaluation generalization of 13 mass transfer equations for determining free water evaporation. Hydrological Processes, 1997, 11: 311-323.

[16] Abtew W, Vbeysekera J, Iricanin N. Pan evaporation and potential evaporation trends in south Florida. Hydrological Processes, 2011, 25: 958-969.

[17] Armstrong RN, Pomeroy JW, Martz LW. Evaluation of three evaporation estimating method in a Canada prairie landscape. Hydrological Prosesses, 2008, 22: 2801-2815.

[18] Valiantzas JD. Simplified versions for the Penman evaporation equation using routine weather data. Journal of Hydrology, 2006, 331: 690-702.

[19］张武忠, 张少波, 王诗俊. 呼伦贝尔市水面蒸发量折算系数分析. 东北水利水电, 2006, (4) : 26-27.

[20] Crapper PF, Fleming PM, Kalmab JD. Prediction of lake levels using water balance models. Environmental Software, 1996, 2(4) : 251-258.

[21］白美兰, 郝润全, 沈建国. 近 46a 气候变化对呼伦湖区域生态环境的影响. 中国沙漠, 2008, 28(1) : 101-107.

[22] 赵慧颖, 乌力吉, 郝文俊. 气候变化对呼伦湖湿地及其周边地区生态环境演变的影响. 生态学报, 2008, 28 (3): 1065-1071. 